\title{
The effects of increased dopamine-levels on attentional control during reading and reading comprehension
}

\author{
Elise K. Swart ${ }^{1,2}$ (D) Maria T. Sikkema-de Jong ${ }^{1,2} \mathbb{D}$
}

Accepted: 4 October 2021

(c) The Author(s) 2021

\begin{abstract}
The aim of the present study was to gain insight into the neurobiological processes, particularly the dopaminergic processes, underlying attentional control during reading and reading comprehension. In order to test the effects of increased levels of dopamine (DA) in the brain, female university students $(N=80)$, half of them being carriers of the DRD4-7R allele and half of them not, participated in a double-blind placebo-controlled within-subjects experiment in which they were orally administered levodopa or a placebo before reading a text. After reading the text, participants reported on their attentional control during reading and completed comprehension questions. Pharmacologically increasing DA levels in the brain negatively influenced reading comprehension. This effect was moderate $\left(\eta_{\mathrm{p}}{ }^{2}=.13\right)$. No interaction effects of condition and DRD4 genotype were found, for either attentional control or reading comprehension. Exploratory analyses showed that increased DA levels in the brain positively influenced fluctuations in attentional control, but only in a group of slow readers. No effects of increased DA were found for the two other attentional control measures used in the present study and no effects of increased DA on attentional control were found for fast readers. Results are discussed from the perspective of the inverted U-shape theory and the possible dopamine-related mechanisms.
\end{abstract}

Keywords Dopamine $\cdot$ Attentional control $\cdot$ Reading comprehension $\cdot$ Inverted U-shape theory

\section{Introduction}

This study was registered with EudraCT European Clinical Trials Database (Identifier: 2014-001,352-36). On behalf of all authors, the corresponding author states that there is no conflict of interest. We acknowledge dr. A.G. Bus for her input to the design of the study at the start of the project and dr. R.C.A. Rippe for his statistical advice.

Reading texts requires the reader to control attention for a longer period of time in order to encode and integrate the information into a coherent mental representation of the text (see e.g., van den Broek et al., 2005). This mental representation is constructed by extracting meaning from the text, and the quality of the mental representation is related

Elise K. Swart

e.k.swart@fsw.leidenuniv.nl

1 Department of Education and Child Studies, Leiden University, P.O. Box 9555, 2300 RB Leiden, The Netherlands

2 Leiden Institute for Brain and Cognition (LIBC), Leiden, The Netherlands to the ability of the reader to learn from texts (van den Broek et al., 2005). Research has shown that people who are better able to control their attention during reading learn more from the texts they read (e.g., Arrington et al., 2014; Sanders et al., 2017; Zhou et al., 2020). Conners (2009) argued that attentional control should be seen as a third and fundamental component of reading comprehension, just as decades of research have shown for the two other components of reading comprehension - decoding and language comprehension - according to the Simple View of Reading (Gough \& Tunmer, 1986). In line with Arrington et al.'s (2014) and Conners' (2009) research on attentional control and reading comprehension, in the present study we defined attentional control as an umbrella construct referring to the allocation of attentional processes and resources. Previous research on attentional control and reading comprehension showed that sustained attention, or vigilance, and cognitive inhibition are two fundamental aspects of attentional control, which both play a unique role in reading comprehension (Arrington et al., 2014). On the one hand, sustained attention helps the reader to maintain focus on relevant information in 
the text. On the other hand, cognitive inhibition helps to prevent irrelevant information (i.e., distracting thoughts, also called mind wandering, or information that is no longer relevant for constructing a mental representation of the text) from creating an overload on working memory. These two abilities regulate the contents of working memory during reading, thereby facilitating the understanding of a text. In line herewith, in the present study we use attentional control measures that mainly focus on or are related to these two core concepts of attentional control during reading: (1) self-reporting moments of distracting thoughts, also referred to as mind wandering, and (2) frontal theta/beta ratio (TBR) during reading, a measure that has been related to self-reports about focusing and shifting attention (see e.g., Putman et al., 2014; Swart et al., 2020; van Son et al., 2019).

Several lines of research have focused on training attentional control via action video games (Green \& Bavelier, 2012), mindfulness and meditation, (Chiesa et al., 2011), and cognitive training (e.g., Karbach \& Verhaeghen, 2014). Studies have shown positive effects of training on performance on neuropsychological tasks demanding attentional control, yet few however have examined whether or not this improved performance transfers to other, real-world tasks (see Owen et al., 2010).

Specific to reading comprehension, the effects of attentional control training have varied. For example, Zanesco et al. (2016) found that meditation training improved attentional control during reading, yet the improved attentional control did not lead to improved reading comprehension. Sanders et al. (2017) found that instructing readers to monitor their attention during reading resulted in better attentional control during reading, but negatively influenced reading comprehension, whereas instructing readers to focus on the construction of a mental representation of the text resulted in improved reading comprehension, but had no effect on attentional control. Finally, Mrazek et al. (2013) found positive effects of a mindfulness training on both attentional control during reading and reading performance.

In sum, research thus far has not provided a clear picture of the relation between attentional control training and reading comprehension. The mixed results may relate to the complex role that DA plays in attentional control (Cools \& D'Esposito, 2011). For example, one of the methods used to train attentional control in the studies just described was meditation, an intervention in which people consciously and continuously try to control their attention. A side effect of meditation is a large increase in DA levels in the brain (Kjaer et al., 2002). In the present study we aim to investigate the role of DA in attentional control to gain more insight into individual differences in attentional control during reading and how this is related to reading comprehension.

\section{The role of DA in attentional control}

DA plays a key role in sustaining attention over prolonged periods of time during completion of tasks, such as reading long stretches of text, that require working memory to integrate information and update knowledge in memory (Boulougouris \& Tsaltas, 2008; Westbrook \& Braver, 2016). Studies with patients who suffer from reduced DA transmission in the brain due to for instance Parkinson's disease, ADHD, or brain lesions have shown that the ability to focus attention decreases, and distractibility increases, when the transmission of DA in the brain is impaired (Nieoullon, 2002). The prefrontal cortex, which is a DA rich area in the brain, is particularly involved in attentional control, and is highly sensitive to fluctuations in DA (see also Cools \& D'Esposito, 2011; Shaywitz \& Shaywitz, 2008).

DA levels in the brain can be pharmacologically manipulated by administering drugs containing levodopa. Levodopa is a precursor of DA, acting on DA receptors in, amongst other brain areas, the prefrontal cortex. Levodopa can restore decreased uptake of DA in the brain, resulting in higher DA levels and enhanced cognitive performance. This effect has been found in both clinical samples and healthy adults (see Moustafa et al., 2013). In line herewith, we wondered whether higher DA levels in the brain during reading might be beneficial for attentional control during reading. Although the number of DA administration studies involving cognitive outcomes has increased over the last ten to fifteen years, the exact influence of DA levels in different brain areas that are related to attentional processes (e.g., prefrontal cortex, anterior cingulate cortex, basal ganglia or caudate nucleus; see Shaywitz \& Shaywitz, 2008) and performance on different kinds of cognitive tasks has not yet become clear (see Diamond et al., 2004; Nieoullon, 2002; Westbrook \& Braver, 2016). Performance on some neuropsychological tasks that require attention (e.g., the dots-mix task) appeared to be sensitive to fluctuations in DA levels (particularly fluctuations in the prefrontal cortex; see Diamond et al., 2004), while performance on other tasks (e.g., a card sorting task tapping into cognitive flexibility) was not (Ko et al., 2009).

\section{The role of DA in memory formation}

DA is not only involved in attentional processes, but also in related processes such as memory formation (see e.g., Boulougouris \& Tsaltas, 2008; Nieoullon, 2002). Similar to the results of the studies on DA and attention, the results of studies on DA and memory formation are mixed (see e.g., Cools \& Robbins, 2004). For example, both Breitenstein et al., (2006a, b) and Knecht et al. (2004) found positive results associated with increased levels of DA on memory. Breitenstein et al., (2006a, b) found that healthy adults who 
were administered either levodopa or D-amphetamine (both aimed to increase DA levels in the brain) performed better on a word-learning task than adults in a placebo control group. Participants learned faster, learned more, and had better retention after one month when administered either levodopa or D-amphetamine. Similarly, Knecht et al. (2004) found that healthy adults who were administered levodopa learned faster, learned more, and had better retention than those in a placebo control group.

In other studies, however, no or negative effects of increased levels of DA were found. For example, Linssen et al. (2014) found that pharmacologically increasing DA levels in healthy adults with the same dose that was used in the studies by Knecht et al. (2004) and Breitenstein et al., (2006a, b) had negative effects on memory performance on a word learning task. Participants had to remember as many words as possible from a list of 30 words that was shown to them three times. Based on EEG data recorded during the word learning task Linssen et al. (2014) argued that administering levodopa slowed down memory processes during the task as was shown by delayed latencies of ERP components (P3b and P600) during the encoding phase of the word learning task. Nevertheless, behavioural data showed that performance on the word learning tasks, as well as two working memory tasks and an associate learning task were not influenced in a positive or negative way by the drug administration.

In sum, although there are some indications that on a neurobiological level increased DA levels in the brain have a negative effect on memory formation, on a behavioural level, negative effects are absent and in some studies even positive effects on memory performance were found.

\section{Explaining the diverging effects of increased DA on cognitive performance}

Linssen et al. (2014) used the inverted U-shape theory as a possible explanation for not finding effects of pharmacologically increasing DA levels in the brain on (working) memory performance of healthy adults. According to this theory, the relation between DA levels in the brain and attention and memory formation follows an inverted U-shape (Vijayraghavan et al., 2007), that is, that both 'too-high' and 'too-low' levels can hinder cognitive performance. However, this theory does not explain the positive effects of pharmacologically increasing DA on memory performance that have been found in other studies with healthy adults (e.g., Breitenstein et al., 2006a, b; Knecht et al., 2004), who are expected to have optimal or close to optimal DA levels. As a consequence, a direct test for the inverted U-shape theory is needed. Therefore, in the present study we test the effects of increased levels of DA in a subgroup of people who are expected to have a well-functioning dopaminergic system, i.e., optimal DA transmission in the brain, and in a subgroup of people with reduced levels of DA transmission in the brain.

One gene that is found to be related to both levels of DA in the brain and attentional control, is the dopamine D4 receptor (DRD4) gene (Bonvicini et al., 2020). People who are carrier of the DRD4 7-repeat allele (DRD4-7R), sometimes referred to as 'the long variant', show suboptimal levels of DA transmission or functioning, as shown by blunted dopamine responses, reduced binding affinities, and reduced receptor densities for dopamine neurotransmission (se e.g., Ariza et al., 2012; Schoots \& van Tool, 2003) compared to people carrying other variants of the allele. Carrying the DRD4-7R allele also has been shown to be a risk factor for ADHD, a disorder marked by difficulties in attentional control (see e.g., Bonvicini et al., 2020). In line with this reasoning, people carrying the DRD4-7R may benefit more from increased levels of DA in the brain than people who carry other polymorphisms of the DRD4 gene.

Whereas carrying the DRD4 7-repeat allele might be one factor distinguishing between higher and lower levels of DA transmission in the brain, other factors related to dopamine functioning might also be indices of baseline DA functioning. Therefore, in the present study we exploratory investigate three other factors that might relate to the expected differences in the effects of increased DA levels on attentional control or reading comprehension. First, DA has been related to the motivation to invest effort in a task (see e.g., Berke, 2018; McGuigan et al., 2019). Lower DA levels have been related to lower motivation. Consequently, motivation might be used as an index of baseline DA functioning. Second, both DA and more specifically the DRD4 7-repeat allele, have been associated to different executive functions, such as inhibition, impulsivity and attention. Therefore, in the present study we investigate self-reported executive functioning in daily life as possible index of DA functioning. Third, DA has been associated to slowdowns in memory processing, with reduced DA functioning being related to slower cognitive processing (see e.g., Jokinen et al., 2013; Linssen et al., 2014). As a consequence, baseline reading speed (i.e., reading speed in the placebo condition) might be used as an index of DA functioning.

\section{Present study}

The aim of the present study is to investigate the effects of increased levels of DA on attentional control during reading and reading comprehension. To achieve this aim, we pharmacologically manipulated the DA levels in the brains of healthy female university students using a similar dosage of levodopa as was used in previous studies (e.g., Breitenstein et al., 2006a, b; Knecht et al., 2004; Linssen et al., 2014). To the best of our knowledge, the present study is the first 
one testing the effects of pharmacologically manipulating DA in the case of reading comprehension. Additionally, our research expands the current literature by directly testing the inverted U-shape theory. Because the effects of increased DA may differ as a consequence of differences in baseline levels of DA transmission in the brain, we investigated the effect of increased DA in two subgroups that are expected to differ in baseline levels of DA transmission in the brain: students who were carrier of the DRD4-7R allele and students who were not.

The present study employs a placebo-controlled double blind within-subjects experiment, in which healthy female students completed a reading task in two conditions (levodopa or placebo), after which their reading comprehension was measured. Based on previous research on DA and attentional control (see e.g., Boulougouris \& Tsaltas, 2008; Nieoullon, 2002; Westbrook \& Braver, 2016), we expect that administering levodopa will influence attentional control during reading. Additionally, in line with previous studies on the effects of administering levodopa on memory formation and word learning tasks (see Breitenstein et al., 2006a, b; Knecht et al., 2004; Linssen et al., 2014), we also expected administering levodopa to influence reading comprehension. In line with the inverted U-shape theory (Boulougouris \& Tsaltas, 2008; Cools \& D'Esposito, 2011; Vijayraghavan et al., 2007) and the fact that the DRD4-7R allele is related to reduced levels of DA transmission (Ariza et al., 2012), we expected, on the one hand, that positive effects of levodopa would be particularly prominent in students carrying the DRD4-7R allele (i.e., less optimal levels of DA transmission), and on the other hand that increases in DA levels would result in a decrease in attentional control during reading and reading performance in the subgroup of students not carrying the DRD4-7R allele. Although we expect carrying the DRD4 7-repeat allele to distinguish between optimal and suboptimal DA transmission, we exploratory investigated reading motivation, self-reported executive functioning in daily life, and baseline reading speed. We proposed that these factors might also function as indices of baseline DA functioning, and could therefore be related to the effect of increased DA levels on attentional control and reading comprehension. Finally, in order to get a more thorough understanding of the effects of increased DA on attentional control and reading comprehension we investigated the relation between effects of increased DA on attentional control and on reading comprehension.

The present study takes a multimethod approach to measure attentional control during reading by measuring attentional control on both a biophysiological level and behavioural level. Recent research has shown that EEG data, specifically frontal TBR might provide a biophysiological marker of attentional control during reading (Swart et al., 2020). In line with previous research on the relation between attentional control, fluctuations in attentional control, and (fluctuations in) frontal TBR in other cognitive tasks (e.g., van Son et al., 2019), the study of Swart et al. (2020) showed that both the average frontal TBR and fluctuations in frontal TBR are related to attentional control and fluctuations in attentional control. We take a similar multi-method approach to gain a thorough understanding of the effect of increased DA on reading comprehension, in the present study we investigate comprehension on both text-level and word-level. For text-level comprehension we combined two tasks, a summary writing task and reading comprehension questions. For word-level comprehension, we take both the breadth (i.e., the number of words participants learn after reading) and depth (i.e., knowledge on both word form and semantics; see e.g., Nation, 2020) of word-level comprehension into account by combining four tasks that each tap into different levels of knowledge about the words in the text, ranging from questions on word form level to questions on passive and active semantic knowledge of a word.

\section{Method}

\section{Research design}

The experiment had a randomized, double-blind placebocontrolled within-subjects design. A total of 80 participants were submitted to two experimental conditions (levodopa and placebo) at two separate lab sessions. In the levodopa condition, participants were administered Sinemet125 (containing $100 \mathrm{mg}$ levodopa and $25 \mathrm{mg}$ carbidopa) at the beginning of the lab session, in the placebo condition participants took a placebo capsule. All medication was produced in identical capsules. To ensure that the study design was double-blind, randomization of the order of treatments (levodopa or placebo) and the order of texts that were read in both experimental sessions (text $\mathrm{A}$ and text $\mathrm{B}$ ) was carried out by the university hospital pharmacy, resulting in four different combinations of the order of treatment condition and text. Before starting the research, its design and methodology were approved by the Education and Child Studies ethics committee of Leiden University (project ID: ECPW2014/077) and the medical ethics committee of the Leiden University Medical Centre (project ID: NL49379.058.14).

\section{Participants}

An initial sample of 200 Dutch female undergraduate students were recruited via advertisements placed in university buildings and student houses and on social media. The total number of recruited students was based on the world-wide average prevalence of the DRD4 7-repeat genotype (20.7\%; 
e.g., Chang et al., 1996). In order to end up with 40 participants with the DRD4 7-repeat allele, approximately five times as much participants had to be recruited. Because of gender differences in DA levels in the brain between men and women (see e.g., Munro et al., 2006) and the large proportion of female students within the faculty, it was decided to include only female participants. Participants had to be 18 years or older and right-handed. Students with dyslexia, medical illnesses indicating a risk in using haloperidol (e.g., cardiac illness, depression, thyroid disorders, or glaucoma), or known drug allergies, and students who were pregnant or lactating were excluded from participation in the study. Students also were excluded if they were using medication (other than contraceptives) or drugs in the two weeks prior to the experiment. After genotyping, 80 students $\left(M_{\text {age }}\right.$ 21.38 years, $S D=1,84$; 40 participants carrying the DRD4$7 \mathrm{R}$ allele, and 40 participants who did not) were selected to participate in the experimental sessions.

\section{Procedures}

Buccal swabs were collected from all participants. DNA was isolated and variable number of tandem repeats (VNTR) genotyping was performed for the DRD4-gene by an external genomics company. Based on these results, participants were grouped in two subgroups: one group of participants carrying at least one DRD4 7-repeat allele (DRD4 7+) and one group carrying two shorter alleles (DRD4 7-). From the 40 students carrying the DRD4 7-repeat allele, 29 students carried one 7-repeat allele and 11 students carried two 7-repeat alleles. Due to the low number of students carrying two 7-repeat alleles, we combined both genotypes in one group of DRD4 7 + students. Each student that was selected after genotyping participated in two lab sessions on two separate days. Students were not informed about the individual results of the genotyping, so they were unaware of the genotype they carried.

At the beginning of the lab sessions, participants received capsules containing either Sinemet125 (release time of the ingredients is approximately $30 \mathrm{~min}$; IBM Micromedex) or the placebo and took the capsules orally. The experiment was double-blind, which means that neither the participant, nor the experimenter knew whether Sinemet 125 or the placebo was given to the participant. Except for one participant reporting nausea in the placebo condition, no side effects of the medication were reported by the participants. Immediately after administering the capsules during the first session, measures of executive functioning in daily life, attentional control, reading motivation and language skills were administered to control for comparability on these factors across the DRD4 7+and DRD4 7- groups (for details on the measurement instruments for these background variables, see Online Resource 1).

Forty-five to sixty minutes after administration, the participant read a narrative text of approximately 4000 words on a computer screen. Participants read one of two passages from a Dutch translation of the novel A Clockwork Orange (Burgess, 2012) that were selected for the present study. The passages were taken from two separate chapters of the book and were understandable without knowing the rest of the storyline. Events in the two chapters did not necessarily have to take place in the order in which the events actually appeared in the book, making counterbalancing of the order of the two texts possible. Text A consisted of 4049 words divided among 16 pages, and text $B$ consisted of 4098 words divided among 17 pages. The texts respectively included 201 (text A, 5.0\% of the total number of words) and 188 (text $\mathrm{B}, 4.6 \%$ of the total number of words) nonsense words from the fictional Nadsat language that was spoken by some of the characters in the novel.

Attentional control during reading was measured using the average frontal theta/beta-ratio (TBR) during reading and the $S D$ in frontal TBR among the text pages (see Swart et al., 2020) and by a retrospective self-report that was administered directly after reading. Frontal TBR was extracted from the EEG-recording during reading. Immediately after reading the text, participants were provided with a paper version of the text and were asked to mark moments in the text where they remembered being distracted from the text.

After self-reporting their attentional control during reading, participants were asked to write a summary of max. 5000 characters about the story they had just read and to answer open comprehension questions about the text ( 28 for text A and 24 for text B). Subsequently, participants completed four tasks concerning word-level comprehension.

\section{Measurement instruments}

\section{Alternative indicators of baseline DA functioning}

Executive functioning and reading motivation For details on the measurement instruments for executive functioning and reading motivation (which were also used as background variables), see Online Resource 1 in which all background variables are described.

Reading times Reading times (in msec) for each text page were recorded by the EEG software used in this experiment. Reading times for all text pages were summed to calculate the total reading time (in minutes) for each text. 


\section{Frontal TBR during reading as a measure of attentional control during reading}

EEG data were recorded during a baseline period (three minutes eyes-closed and three minutes eyes-open) and during reading. We used 129-channel hydrocel Geodesic sensor nets and electrodes, which were placed according to the 10-20 system amplified by a NetAmps300 amplifier at a digitization rate of $500 \mathrm{~Hz}$ (Electrical Geodesics Inc.). Impedances were kept below $50 \mathrm{k} \Omega$. Raw data were further processed offline using Brain Vision Analyzer 2.0 software (Brain Products). Data were low-pass filtered at $100 \mathrm{~Hz}(-3 \mathrm{~dB}$, $48 \mathrm{~dB} /$ oct $)$ and high-pass filtered at $0.3 \mathrm{~Hz}(99.9 \%$ pass-band gain, $0.1 \%$ stop-band gain, $1.5 \mathrm{~Hz}$ roll-off) with a notch-filter of $50 \mathrm{~Hz}$ to eliminate electrical noise. Subsequently, EEG data were referenced to the average activity in all channels and ocular correction was performed using the Gratton \& Coles procedure (Gratton et al., 1983). To retain as much artefact-free data as possible, raw EEG data were segmented in $2 \mathrm{~s}$ segments with an overlap of 5\%. Segments containing artefacts (defined as: voltage steps exceeding $50 \mu \mathrm{V} /$ $\mathrm{ms}$, differences in values above $100 \mu \mathrm{V}$ within an interval of $200 \mathrm{~ms}$, amplitudes lower than $-70 \mu \mathrm{V}$ or higher than $70 \mu \mathrm{V}$ or segments containing less than $0.5 \mu \mathrm{V}$ activity in intervals of $100 \mathrm{~ms}$ intervals) were excluded from further analyses. In addition, noisy channels were replaced by average activity of the close electrodes. After segmenting the data and correcting for artefacts, power densities in the theta $(4-7 \mathrm{~Hz})$ and beta $(13-30 \mathrm{~Hz})$ frequency bands were calculated by performing a fast Fourier transformation (resolution $0.25 \mathrm{~Hz}$, hamming window $10 \%$ ).

Frontal TBR during reading was calculated for each text page, based on the average power density of three frontal electrodes (F3, Fz, and F4, represented by electrode numbers 24, 11, and 124 respectively; Putman et al., 2014; Swart et al., 2020). Because of non-normality, power density values within each frequency band were log-normalized before calculating the ratios. The average frontal TBR during reading was calculated by averaging frontal TBR for all text pages within each text. Higher ratios reflected lower attentional control during reading and lower scores reflected better attentional control during reading (see e.g., Putman et al., 2014; van Son et al., 2019). The $S D$ among the average frontal TBRs for each text page within each text was calculated as in indicator for fluctuations in frontal TBR during reading.

\section{Self-reports of attentional control during reading}

For each moment in the text that participants marked as being distracted, the experimenter asked the participant afterwards what she was thinking at that moment. All selfreports were scored by an undergraduate student and the first author to distinguish comments that reflected meaning construction (e.g., "When I read this sentence, I thought back to a scene at the beginning of the text") vs. comments that reflected being distracted during reading (e.g., "At this part of the text I was not paying attention to the text anymore, but I was thinking about what I would buy for dinner after finishing the experiment"). The total number of marked moments that reflected moments of distraction during the text reading task was used as an indicator for attentional control during reading. Disagreements in scoring were resolved through discussion until consensus was reached. Inter-coder reliability was ICC $=0.96(p<0.001)$ for self-reports of attentional control during text A and ICC $=1.00(\mathrm{p}<0.001)$ for selfreports on attentional control during text $\mathrm{B}$.

\section{Text-level summary task (post test)}

Participants' summaries were scored for the number of main elements in the text that were included in the summary. Main elements in the texts were selected based on the EventIndexing Model (Zwaan et al., 1995) and, in line with the model, included information on time, space, protagonists, causality and intentionality of story events. The percentage of correctly mentioned elements for each text was calculated. All summaries were scored by two trained undergraduate students. Inter-coder reliability was ICC $=1.00(p<0.001)$ for the summaries of text A and ICC $=1.00(p<0.001)$ for the summaries of text B. Disagreements in scoring were resolved through discussion until consensus was reached.

\section{Text-level comprehension questions (post test)}

Correct answers on the open comprehension questions about the content of the text (27 for text A and 24 for text B) were awarded one point. If an answer contained two components (e.g., two reasons why the main character in the story did not want to go to school), participants could receive half a point for mentioning one of the two components. A proportion of the correct answers from the maximum scores was calculated for each text. All answers were scored by two trained undergraduate students. Inter-coder reliability was ICC $=0.98(p<0.001)$ for the questions of text A and ICC $=0.96(p<0.001)$ for the questions of text B. Disagreements in scoring were resolved through discussion until consensus was reached.

\section{Word-level comprehension questions (post test)}

Participants completed four tasks concerning 30 of the nonsense words from the fictional Nadsat language that was spoken by some of the characters in the novel. All four tasks concerned the same 30 nonsense words per text. First, participants were asked to fill in a nonsense word that they 
remembered from the text that would fit in one of the 30 new sentences that did not appear in the text (sentence task). Second, participants were shown a list of the 30 nonsense words and were asked to fill in one or two missing letters in each word (spelling questions). Third, participants were shown the 30 nonsense words and were asked to fill in the meaning of the 30 nonsense words (open word meaning questions). Fourth, for each word the participants had to choose the correct Dutch meaning of the nonsense words out of three alternatives (MC word meaning questions). A total score (max. 30 points) was calculated for each task based on the number of correct answers. All answers were scored by two trained undergraduate students. Inter-coder reliability for all word-level comprehension tasks was on average ICC $=0.98$ (range: $0.93-1.00$, all $p$ 's $<0.001$ ). Disagreements in scoring were resolved through discussion until consensus was reached.

\section{Results}

\section{Descriptive results}

The final sample consisted of 40 students with the DRD4 7+genotype and 40 students with the DRD4 7- genotype. Students in the two groups did not differ in age, reading motivation, language skills, executive functioning in daily life, attentional control in daily life, or baseline reading speed (see Table 1). Reading times did not differ between the levodopa condition $(M=18.02 \mathrm{~min}, S D=4.34)$ and the placebo condition $(M=18.64 \mathrm{~min}, S D=5.02, t(78)=1.60$, $p=0.11$ ). Data on all outcome variables were complete for all participants, except for frontal TBR during reading, and the self-reports on attentional control. Missing data were due to technical issues. Frontal TBR data in the levodopa condition were missing for one participant in the DRD4 7+group.
Scores on the self-report on attentional control during reading were missing for two participants in the DRD4 7- group, one in the levodopa condition and one in the placebo condition. One participant had an outlying score $(z>3.29$; Tabachnik \& Fidell, 2007) for frontal TBR in the levodopa condition, $S D$ in frontal TBR in both conditions and on the self-report in both conditions. We excluded this participant from further analyses regarding attentional control. The scores on the sentence completion (word-level comprehension) subtest were highly skewed (standardized skewness placebo condition $=4.67$, levodopa condition $=15.87$ ). This subtest appeared to be too difficult for the participants. In the placebo condition $65.0 \%$ of the participants scored zero points on the test and in the levodopa condition, $72.5 \%$ of the participants scored zero points. The scores on this subtest were, therefore, not included in further analyses. Data for all outcome measures in both conditions broken down by genotype subgroup, are shown in Table 2. For correlations between the attentional control measures and reading comprehension measures in each condition, see Table 3 and 4. Surprisingly all correlations between scores on attentional control measures and reading comprehension measures were weak (Cohen, 1992) and not significant, except for the correlation between $S D$ in frontal TBR and spelling questions in the placebo condition $(r=0.23)$ and the correlation between self-reported moments of mind wandering and spelling questions $(r=0.31)$, which reached significance.

We performed the following repeated measures ANOVAs to test the effects of increasing DA levels (levodopa vs. placebo as a within-subjects factor) on attentional control and reading comprehension both with and without DRD4 genotype as a between-subjects factor. No main effects of DRD4 genotype or interaction effects involving DRD4 genotype were found (for the results, see Online Resource 2). We, therefore, report the results for the model that includes only the within-subjects factors condition (levodopa vs. placebo) and type of outcome measure (for attentional control:
Table 1 Descriptive Statistics for the Background Variables for Participants with the DRD4 7- Genotype $(n=40)$ and the DRD4 7+ Genotype $(n=40)$

\begin{tabular}{llllllll}
\hline Variable & Genotype & Min & Max & \multicolumn{1}{l}{$M$} & $S D$ & $t(78)$ & $p$ \\
\hline Age (in years) & DRD4 7- & 18 & 27 & 21.58 & 2.01 & 0.82 & .41 \\
& DRD4 7+ & 18 & 24 & 21.18 & 1.65 & & \\
Reading Motivation & DRD4 7- & -3.63 & 1.66 & -0.11 & 1.05 & -0.83 & .41 \\
& DRD4 7+ & -2.20 & 2.03 & 0.11 & 0.95 & & \\
Language skills & DRD4 7- & -1.60 & 1.63 & -0.03 & 0.93 & -0.19 & .85 \\
& DRD4 7+ & -1.78 & 3.53 & 0.03 & 1.08 & & \\
Executive functioning (BRIEF-A) & DRD4 7- & 78 & 167 & 114.13 & 20.81 & 0.52 & .60 \\
& DRD4 7+ & 75 & 178 & 111.62 & 21.86 & & \\
Attentional Control (ACS) & DRD4 7- & 31 & 76 & 53.30 & 9.01 & -0.39 & .70 \\
& DRD4 7+ & 40 & 69 & 53.80 & 8.00 & & \\
Baseline reading speed (in minutes) & DRD4 7- & 11.30 & 32.80 & 18.36 & 4.74 & -0.38 & .70 \\
& DRD4 7+ & 10.63 & 40.70 & 18.80 & 5.33 & & \\
\hline
\end{tabular}


Table 2 Descriptive Statistics for Outcome Measures in the Levodopa Condition and the Placebo Condition, Separated per Subgroup of Genotype $(N=80)$

\begin{tabular}{|c|c|c|c|c|c|c|c|}
\hline \multirow[t]{2}{*}{ Outcome measure } & \multirow[t]{2}{*}{ Subgroups } & \multicolumn{3}{|c|}{ Levodopa condition } & \multicolumn{3}{|c|}{ Placebo condition } \\
\hline & & $n$ & $M$ & $S D$ & $n$ & $M$ & $S D$ \\
\hline \multirow[t]{3}{*}{ Average frontal TBR during reading } & DRD4 7- & 40 & .40 & .24 & 40 & .40 & .18 \\
\hline & DRD4 7+ & 39 & .39 & .16 & 40 & .38 & .17 \\
\hline & Total & 79 & .40 & .20 & 80 & .39 & .17 \\
\hline \multirow[t]{3}{*}{$S D$ in frontal TBR during reading } & DRD4 7- & 39 & .09 & .07 & 39 & .08 & .05 \\
\hline & DRD47+ & 39 & .10 & .05 & 40 & .09 & .06 \\
\hline & Total & 78 & .09 & .06 & 79 & .09 & .05 \\
\hline \multirow[t]{3}{*}{ Self-reported attention during reading } & DRD4 7- & 39 & 3.33 & 2.85 & 39 & 3.23 & 3.07 \\
\hline & DRD4 7+ & 40 & 2.85 & 2.03 & 40 & 2.73 & 2.45 \\
\hline & Total & 79 & 3.09 & 2.47 & 79 & 2.97 & 2.76 \\
\hline \multirow[t]{3}{*}{ Summary task ( $\%$ correct mentioned main events) } & DRD4 7- & 40 & 24.21 & 13.44 & 40 & 24.29 & 13.54 \\
\hline & DRD4 7+ & 40 & 25.18 & 13.93 & 40 & 26.66 & 12.79 \\
\hline & Total & 80 & 24.70 & 13.61 & 80 & 25.47 & 13.14 \\
\hline \multirow[t]{3}{*}{ Text-level comprehension questions ( $\%$ correct) } & DRD4 7- & 40 & 33.73 & 19.47 & 40 & 37.66 & 19.32 \\
\hline & DRD4 7+ & 40 & 29.90 & 15.59 & 40 & 35.78 & 15.91 \\
\hline & Total & 80 & 31.82 & 17.63 & 80 & 36.72 & 17.61 \\
\hline \multirow[t]{3}{*}{ Spelling questions ( $\%$ correct) } & DRD4 7- & 40 & 7.75 & 5.62 & 40 & 10.67 & 6.97 \\
\hline & DRD4 7+ & 40 & 8.92 & 5.91 & 40 & 10.33 & 8.80 \\
\hline & Total & 80 & 8.33 & 5.76 & 80 & 10.50 & 7.89 \\
\hline \multirow[t]{3}{*}{$\mathrm{MC}$ word meaning questions ( $\%$ correct) } & DRD4 7- & 40 & 45.08 & 9.31 & 40 & 45.67 & 12.43 \\
\hline & DRD4 7+ & 40 & 42.92 & 9.52 & 40 & 48.08 & 14.65 \\
\hline & Total & 80 & 44.00 & 9.42 & 80 & 46.88 & 13.56 \\
\hline \multirow[t]{3}{*}{ Open word meaning questions ( $\%$ correct) } & DRD4 7- & 40 & 4.58 & 5.37 & 40 & 6.25 & 6.32 \\
\hline & DRD4 7+ & 40 & 5.00 & 5.99 & 40 & 6.58 & 8.08 \\
\hline & Total & 80 & 4.79 & 5.66 & 80 & 6.42 & 7.21 \\
\hline
\end{tabular}

Table 3 Correlations Among Outcome Measures for Attentional Control and Reading Comprehension in the Placebo Condition $(N=80)$

Table 4 Correlations Among Outcome Measures for Attentional Control and Reading Comprehension in the Levodopa Condition $(N=80)$

\begin{tabular}{lllllllll}
\hline & 1 & 2 & 3 & 4 & 5 & 6 & 7 & 8 \\
\hline 1. Average frontal TBR during reading & 1 & & & & & & & \\
2. $S D$ in frontal TBR during reading & .02 & 1 & & & & & & \\
3. Self-reported attentional control during reading & .13 & -.13 & 1 & & & & & \\
4. Summary writing task & -.01 & .12 & -.05 & 1 & & & & \\
5. Text-level comprehension questions & .04 & .03 & -.20 & $.29 * *$ & 1 & & & \\
6. Spelling questions & -.08 & $.23^{*}$ & -.04 & .18 & .17 & 1 & & \\
7. MC word meaning questions & -.19 & .13 & -.13 & -.02 & $.34^{* *}$ & $.45^{* *}$ & 1 & \\
8. Open word meaning questions & -.07 & .16 & -.01 & .01 & -.01 & $.43^{* *}$ & $.36^{*}$ & 1 \\
\hline
\end{tabular}

\begin{tabular}{lllllllll}
\hline & 1 & 2 & 3 & 4 & 5 & 6 & 7 & 8 \\
\hline 1. Average frontal TBR during reading & 1 & & & & & & & \\
2. SD in frontal TBR during reading & -.01 & 1 & & & & & & \\
3. Self-reported attentional control during reading & .02 & .04 & 1 & & & & & \\
4. Summary writing task & .09 & -.03 & -.06 & 1 & & & & \\
5. Text-level comprehension questions & .02 & -.04 & -.17 & .16 & 1 & & & \\
6. Spelling questions & .13 & .07 & $-.31^{* *}$ & .17 & -.01 & 1 & & \\
7. MC word meaning questions & -.15 & -.03 & -.03 & .10 & $.38^{* *}$ & .01 & 1 & \\
8. Open word meaning questions & -.08 & -.05 & -.14 & .09 & .07 & $.28^{*}$ & $.43^{*}$ & 1 \\
\hline
\end{tabular}


average frontal TBR, $S D$ in frontal TBR and self-report; for reading comprehension: summary task, text-level comprehension questions, spelling questions, MC word meaning questions, and open word meaning questions).

\section{The effects of DA on attentional control during reading}

In order to include the scores on the three attentional control measures (average frontal TBR during reading, $S D$ in frontal TBR during reading, and self-reports) in one analysis, we decided in consultation with a statistical expert to calculate the proportion of each score of the maximum observed score for each respective attentional control measure across both conditions and subgroups of DRD4 genotype to end up with similar scales for each measure. A repeated measures ANOVA with condition (levodopa vs. placebo) and type of attentional control measure (frontal TBR during reading, $S D$ in frontal TBR during reading and self-reports of attentional control during reading) as within-subjects factors showed no main effect of condition $(F(1,75)=1.48, p=0.23$, $\left.\eta_{\mathrm{p}}{ }^{2}=0.02\right)$. Attentional control during reading did not differ between the levodopa condition and the placebo condition. The main effect of type of attentional control measure was significant $\left(F(1,75)=40.73 ; p<0.001 ; \eta_{\mathrm{p}}{ }^{2}=0.35\right)$, showing that the proportional scores for the average frontal TBR during reading $(M=0.41 ; S D=0.16), S D$ in frontal TBR during reading $(M=0.25, S D=0.10)$, and scores for the self-reports $(M=0.22 ; S D=0.15)$ varied. No interaction effect was found for condition and type of attentional control measure on attentional control during reading $(F(1,75)=1.27, p=0.29$, $\eta_{\mathrm{p}}^{2}=0.02$ ).

\section{The effects of DA on reading comprehension}

A repeated measures ANOVA was performed with condition (levodopa vs. placebo) and type of reading comprehension measure (summary task, text-level comprehension questions, spelling questions, open word meaning questions, and $\mathrm{MC}$ word meaning questions) as within-subjects factors. Mauchly's test indicated that the assumption of sphericity had been violated for the main effect of type of outcome measure $\left(\chi^{2}(9)=116.95, p<0.001\right)$ and the interaction effect of condition and type of outcome measure $\left(\chi^{2}\right.$ $(9)=110.45, p<0.001)$. Therefore, degrees of freedom for these effects were corrected using Greenhouse-Geisser estimates of sphericity ( $\varepsilon=0.62$ for the main effect of condition and $\varepsilon=0.57$ for the interaction effect of condition and type of outcome measure). There was a significant main effect of condition on reading comprehension $(F(1,79)=11.55$, $\left.p=0.001, \eta_{\mathrm{p}}{ }^{2}=0.13\right)$. Participants performed worse on reading comprehension in the levodopa condition than in the placebo condition. This effect was moderate. The main effect of type of reading comprehension measure was significant $\left(F(2.50,197.19)=334.77, p<0.001, \eta_{\mathrm{p}}{ }^{2}=0.81\right)$, showing that the mean scores of participants varied among the comprehension tasks. In other words, participants perceived some tasks as more difficult than others, particularly the spelling task and the open word meaning questions (for means and $S D$ s, see Table 5). No significant interaction effect of condition and type of outcome measure on reading comprehension was found $(F(2.27,179.51)=0.93, p=0.41$, $\left.\eta_{\mathrm{p}}{ }^{2}=0.01\right)$. Levodopa had a similar effect on the different comprehension measures.

\section{Exploring alternative indices of DA functioning in relation to the effects of increased DA on attentional control and reading comprehension}

We performed repeated measures ANOVAs to investigate the effects of increasing DA levels on attentional control and reading comprehension in relation to three possible indices of DA functioning - reading motivation, executive functioning, and baseline reading speed. In order to divide the participants into two sub-groups of expected low and high baseline DA functioning, we performed a median split on the scores for respectively reading motivation, self-reported executive functioning as measured by the total score on the BRIEFA, and participants' baseline reading speed. For descriptive statistics for all outcome measures separated for (1) low and high reading motivation, (2) low and high executive functioning, and (3) slow and fast readers, see Online Resource 3. In the following sections, we describe the main effects of the three between-subject factors and the interaction effects of these factors with condition on attentional control and reading comprehension. For all statistics and results of the RM-ANOVAs, see Online Resource 3.

\section{Low vs. high reading motivation}

A repeated measures ANOVA with condition (levodopa vs. placebo) and type of attentional control measure (frontal TBR during reading, $S D$ in frontal TBR during reading and self-reports of attentional control during reading) as withinsubjects factors and reading motivation (low vs. high) as

Table 5 Estimated Marginal Means of the Main Effect of Type of Reading Comprehension Measure $(N=80)$

\begin{tabular}{lrl}
\hline Reading comprehension measure & $M$ & $S E$ \\
\hline Summary task & 25.08 & 1.23 \\
Text-level comprehension questions & 34.27 & 1.59 \\
Spelling questions & 9.42 & 0.62 \\
MC word meaning questions & 5.60 & 0.52 \\
Open word meaning questions & 45.43 & 1.00
\end{tabular}


between-subjects factor showed no main effect of reading motivation $\left(F(1,74)=0.00, p=1.00, \eta_{\mathrm{p}}{ }^{2}=0.00\right)$ and also no interaction effect of reading motivation and condition on attentional control $\left(F(1,74)=0.30, p=0.59, \eta_{\mathrm{p}}{ }^{2}=0.004\right)$. In other words, reading motivation did not affect attentional control during reading and no differences in the effects of increased DA levels on attentional control were found between students with low or high reading motivation.

A repeated measures ANOVA with condition (levodopa vs. placebo) and type of reading comprehension measure (summary task, text-level comprehension questions, spelling questions, open word meaning questions, and MC word meaning questions) as within-subjects factors and reading motivation (low vs. high) as between-subjects factor showed no main effect of reading motivation $\left(F(1,78)=2.65, p=0.11, \eta_{\mathrm{p}}{ }^{2}=0.03\right)$ and also no interaction effect of reading motivation and condition on reading comprehension $\left(F(1,78)=0.53, p=0.47, \eta_{\mathrm{p}}{ }^{2}=0.01\right)$. In other words, reading motivation did not affect reading comprehension and no differences in the effects of increased DA levels on reading comprehension were found between students with low or high reading motivation.

\section{Low vs. high executive functioning}

A repeated measures ANOVA with condition (levodopa vs. placebo) and type of attentional control measure (frontal TBR during reading, $S D$ in frontal TBR during reading and selfreports of attentional control during reading) as within-subjects factors and executive functioning (low vs. high) as betweensubjects factor showed no main effect of executive functioning $\left(F(1,74)=0.20, p=0.66, \eta_{\mathrm{p}}{ }^{2}=0.003\right)$ and also no interaction effect of executive functioning and condition on attentional control $\left(F(1,74)=0.02, p=0.89, \eta_{\mathrm{p}}{ }^{2}=0.00\right)$. In other words, selfreported executive functioning did not affect attentional control during reading and no differences in the effects of increased DA levels on attentional control were found between students with low or high self-reported executive functioning.

A repeated measures ANOVA with condition (levodopa vs. placebo) and type of reading comprehension measure (summary task, text-level comprehension questions, spelling questions, open word meaning questions, and MC word meaning questions) as within-subjects factors and executive functioning (low vs. high) as between-subjects factor showed a main effect of executive functioning $(F(1,78)=4.44$, $\left.p=0.04, \eta_{\mathrm{p}}{ }^{2}=0.05\right)$ on reading comprehension. Students who reported to have better developed executive functions scored higher on reading comprehension than students scoring lower on executive functions. Results showed no interaction effect of executive functioning and condition on reading comprehension $\left(F(1,78)=1.48, p=0.23, \eta_{\mathrm{p}}{ }^{2}=0.02\right)$, meaning that no differences in the effects of increased DA levels on reading comprehension were found between students with low or high self-reported executive functions.

\section{Slow vs. fast baseline reading speed}

A repeated measures ANOVA with condition (levodopa vs. placebo) and type of attentional control measure (frontal TBR during reading, $S D$ in frontal TBR during reading and self-reports of attentional control during reading) as withinsubjects factors and baseline reading speed (slow vs. fast) as between-subjects factor showed no main effect of baseline reading speed $\left(F(1,74)=0.00, p=0.96, \eta_{\mathrm{p}}{ }^{2}=0.00\right)$. However, the interaction of baseline reading speed and condition was significant and moderate $(F(1,74)=6.00, p=0.02$, $\left.\eta_{\mathrm{p}}{ }^{2}=0.08\right)$. Readers with a lower baseline reading speed showed increased attentional control in the levodopa condition compared to the placebo condition. For readers with a higher baseline reading speed, no differences in attentional control were found between the levodopa condition and the placebo condition.

To understand the interaction effect of condition and baseline reading speed on attentional control, for the group with lower baseline reading speed we performed three follow-up repeated measures ANOVAs with condition as within-subjects factor (levodopa vs. placebo) and average frontal TBR, $S D$ in frontal TBR, and self-report as outcome measures. No difference in average frontal TBR was found between the placebo $(M=0.40, S D=0.20)$ condition and the levodopa condition $(M=0.38, S D=0.16), F(1,38)=0.18$, $p=68, \eta_{\mathrm{p}}{ }^{2}=0.01$. For $S D$ in frontal TBR, a significant difference was found between the placebo condition $(M=0.32$, $S D=0.20)$ and the levodopa condition $(M=0.22, S D=0.12)$, $F(1,38)=6.17, p=0.02, \eta_{\mathrm{p}}{ }^{2}=0.14$. Slow readers showed less fluctuations in frontal TBR after administering levodopa than after administering a placebo. For self-reported attentional control, no differences were found between the placebo condition $(M=0.21, S D=0.12)$ and the levodopa condition $(M=0.20, S D=0.14), F(1,38)=0.02, p=0.88$, $\eta_{\mathrm{p}}^{2}=0.001$.

To test for possible interaction effects of condition and baseline reading speed on reading comprehension, a repeated measures ANOVA with condition (levodopa vs. placebo) and type of reading comprehension measure (summary task, text-level comprehension questions, spelling questions, open word meaning questions, and MC word meaning questions) as within-subjects factors and baseline reading speed (slow vs. fast) as between-subjects factors was performed. No main effect of baseline reading speed $\left(F(1,78)=1.18, p=0.28, \eta_{\mathrm{p}}{ }^{2}=0.03\right)$ and also no interaction effect of baseline reading speed and condition on reading comprehension $\left(F(1,78)=0.03, p=0.87, \eta_{\mathrm{p}}{ }^{2}=0.00\right)$ was found. In other words, baseline reading speed did not affect reading comprehension and had no differential effect for increased DA levels on reading comprehension.

We also wondered whether levodopa had a stronger effect on reading speed in participants with lower baseline 
reading speed compared to participants with higher baseline speed. We therefore performed a repeated measures ANOVA with condition (levodopa vs. placebo) as withinsubject factor and baseline reading speed (slow vs. fast) as between-subject factor. No main effect of condition on reading speed $\left(F(1,77)=2.75, p=0.10, \eta_{\mathrm{p}}{ }^{2}=0.03\right)$ was found. However, the interaction of condition and baseline reading speed was significant $\left(F(1,77)=10.67, p=0.02, \eta_{\mathrm{p}}{ }^{2}=0.12\right)$. This effect was moderate and showed that increased DA caused a speeding effect in reading time for the group of slower readers (in minutes; $M_{\text {placebo }}=22.22, S D=4.55$; $\left.M_{\text {levodopa }}=20.41, S D=4.07\right)$, but not for the group of faster readers $\left(M_{\text {placebo }}=14,95, S D=1.78 ; M_{\text {levodopa }}=15.57\right.$, $S D=3.08)$.

For this group of slower readers, the individual differences in reading speed between conditions (placebo vs. levodopa) marginally significantly correlated with individual differences in attentional control between conditions, as measured by the $S D$ in frontal TBR, $(r=0.28, p=0.08)$. In other words, slow readers' individual difference scores in reading speed $(M=-1.81, S D=3.71)$ and $S D$ in frontal TBR $(M=-0.10, S D=0.24)$ tended to be related.

\section{Exploring the relations between drug effects on attentional control and reading comprehension}

We investigated the relations between drug effects (i.e., effects of increased DA levels) on attentional control and drug effects on reading comprehension by computing Pearson's correlations among the difference scores (i.e., score in the levodopa minus the score in the placebo condition) for all attentional control measures and all reading comprehension measures. No significant relations were found between drug effects on attentional control measures on the one hand and reading comprehension measures on the other hand, except for one. Students who self-reported to be distracted more often in the levodopa condition than in the placebo condition scored lower on the text-level comprehension questions in the levodopa condition compared to the placebo condition $(r=0.27, p=0.02)$. In other words, decreased self-reported attentional control as a consequence of increased DA was related to a decrease in text-level reading comprehension as measured by the text-level comprehension questions. For all correlations, see Online Resource 3.

\section{Discussion}

The aim of the present study was to gain insight into the neurobiological processes, particularly dopaminergic mechanisms, underlying attentional control during reading and reading comprehension by investigating the effects of pharmacologically increasing DA. To the best of our knowledge, the present study is the first study to investigate the effects of pharmacologically manipulating DA in the field of reading comprehension. In order to test the effects of increased DA levels in the brain, university students participated in a placebo-controlled within-subject experiment in which they were orally administered either levodopa, a precursor of DA, or a placebo before reading a text. In order to directly test the inverted U-shape theory concerning the effects of DA levels on cognitive performance (see Boulougouris \& Tsaltas, 2008; Cools \& D’Esposito, 2011; Vijayraghavan et al., 2007), two subgroups of students were included in the experiment: one group of students carrying the DRD4 7R allele and one group of students who did not. No differences in attentional control between the DRD4 7 + and the DRD4 7- groups were found at the start of the study. Also, a first set of analyses showed no main effects of DRD4 genotype or interaction effects of DRD4 genotype and condition or type of outcome measure, neither for attentional control during reading nor for reading comprehension. As a consequence, DRD4 genotype was not included as a between-subjects factor in the core analyses of the present study. Results of the core analyses showed that increased levels of DA did not affect attentional control during reading in a positive or negative way, as measured on both a neurobiological and behavioural level. However, on a behavioural level, increased levels of DA influenced reading comprehension in a negative way. That is, students performed significantly worse on the comprehension tasks when reading a text in the levodopa condition than in the placebo condition. This effect was moderate. Exploratory analyses aimed at finding correlates of baseline DA levels showed that reading motivation and executive functioning were not related to the effects of increased DA on attentional control and reading comprehension. Alternatively, the effect of increased DA on attentional control differed for slow and fast readers (as defined by the reading speed in the placebo condition). A positive effect of DA was found for slower readers, whereas no effect was found for faster readers. Also, increased DA caused a speeding effect for slower readers, but not for faster readers. Exploratory correlational analyses on the relations between drug effects (i.e., effects of increased DA levels) on attentional control and on reading comprehension showed that students who self-reported more moments of distraction in the levodopa condition compared to the placebo condition showed a decrease in reading comprehension in the levodopa condition compared to the placebo condition, as measured by text-level comprehension questions. No relations were found between drug effects on other measures for attentional control on the one hand and reading comprehension on the other hand. 


\section{DRD4 genotype and the inverted U-shape theory}

In line with the inverted U-shape theory (see Boulougouris \& Tsaltas, 2008; Cools \& D’Esposito, 2011; Vijayraghavan et al., 2007), we expected that pharmacologically increasing DA levels in the brain would particularly enhance attentional control during reading and reading performance in adults carrying the DRD4 7R allele, which has shown to be related to a less efficient transmission of DA in the brain (Ariza et al., 2012). As a consequence, we expected that the levels of DA in the brain of this group of adults would be situated left from the top of the inverted U-shape and that, therefore, they would be more susceptible for the positive effects of administering levodopa. Contrary to what was expected, there were no differences in attentional control, reading motivation or executive functioning between the two groups at pretest. Also, no differences in baseline reading speed were found between the two subgroups of students. Additionally, no interaction effects of DRD4 genotype and condition on attentional control or reading comprehension were found. This was also the case for interaction effects of reading motivation and executive functioning on the one hand and condition on the other hand on attentional control or reading comprehension. This suggests that students from the DRD4 7+ and DRD4 7-groups did not differ in levels of DA functioning at pretest. A third factor that was used as a possible indicator for baseline DA functioning, namely baseline reading speed, showed a significant interaction effect with condition on attentional control, but not on reading comprehension.

It is possible that the reduced levels of DA functioning that are related to the DRD4 7+genotype are particularly problematic in younger children. Bonvicini et al. (2020) found the DRD4-7R allele to be a major risk factor for ADHD, but only for children. The association was not present for adults. Other studies have also shown that the relation between DRD4 genotype and ADHD symptoms decreases with age (Bonvicini et al., 2018). If all participants, both those who carry the DRD4 7R allele and those who do not, are on average already located near or at the top of the inverted U-shape model regarding the levels of DA functioning, it would mean that pharmacologically increasing DA would have no effect or possibly even a negative effect on attentional control and reading comprehension.

\section{The effects of DA on attentional control during reading}

Despite the key role of DA in attentional control processes that has been found in previous studies (see e.g., Boulougouris \& Tsaltas, 2008; Nieoullon, 2002; Westbrook \& Braver, 2016), increased levels of DA did only decrease fluctuations in attentional control during reading, as measured by fluctuations in frontal TBR during reading, in a group of slower readers. No effects of increased levels of DA on fluctuations in frontal TBR were found for faster readers. Additionally, no effects of increased levels of DA were found for attentional control as measured by the average frontal TBR during reading and by a retrospective self-report. A possible explanation for not finding an effect of increased DA on attentional control during reading might be the limited sensitivity of the average frontal TBR to fluctuations in attentional control while reading the text. Ups and downs in attentional control average out in the overall average frontal TBR for the whole text. As a consequence, no conclusions could be formed on the effect of DA on the amount of fluctuations in attentional control based on this attentional control outcome measure. Nevertheless, the average frontal TBR during reading might still be informative as a broad measure of attentional control during reading. Results from a previous study showed that the average frontal TBR was moderately to strongly related to attentional control in daily life and to text-level reading comprehension (Swart et al., 2020). However, this relation was not replicated in the present study. Although the texts used in both the current and the previous study came from the same chapters of the novel 'A Clockwork Orange', the texts in the present study were 1500 words longer than those used in the previous study, and participants took nearly twice as long to read the longer texts. Longer tasks might evoke more lapses in attention which may not be reflected in an average score of attentional control during reading (see Krimsky et al., 2017). This could also explain the lacking relation between attentional control and reading comprehension in the present study.

Alternatively, the speeding effect that was found for the slower readers as a consequence of administering levodopa was marginally significantly related to the effect of increased DA on $S D$ in frontal TBR. In other words, participants who showed larger speeding effects as a consequence of administering levodopa also tended to show less fluctuations in frontal TBR after administering levodopa. Possibly, this relation could be explained by the fact that shorter task duration might evoke less lapses of attentional control.

Whereas the average frontal TBR provides a broad measure of the average attentional control during reading, the self-report measure of attentional control included in the present study could be informative on the point of fluctuations in attentional control. Possibly, meta-awareness could have confounded the results for this measure. Self-awareness is required for reporting moments of distraction during reading. However, research has shown that readers are not always aware that they fail to control attention. Additionally, it is the lapses in attentional control that readers are not aware of that are most detrimental for memory formation (for a review see Smallwood \& Schooler, 2015). Such lapses are obviously not reflected in a self-report measure. Nevertheless, 
the absence of an effect of increasing DA on self-reports of attentional control is in line with the overall results found for the effects of increased DA on fluctuations in frontal TBR found in the present study. Only for a sub-group of slower readers, increased DA decreased fluctuations in attentional control, as measured by the $S D$ in frontal TBR. The fact that this relation was not found on a behavioral level is in line with the idea of meta-awareness as a prerequisite for reporting these moments of inattention.

Although one could argue that processing speed could be proposed as an alternative indicator of baseline DA functioning, we did not find other possible indicators of baseline DA functioning - DRD4 7-repeat genotype, reading motivation, and executive functioning in daily life - to be related to the effects of increased DA on attentional control or reading comprehension. As a consequence, the proposed relation between baseline reading speed and baseline DA has to be interpreted with some caution.

\section{The effects of dopamine on reading comprehension}

In line with previous studies on the effects of administering levodopa on memory formation and word learning tasks (see Breitenstein et al., 2006a, b; Knecht et al., 2004; Linssen et al., 2014), we expected administering levodopa to influence reading comprehension. In the present study we found that administering levodopa negatively influenced reading comprehension, i.e., the formation of a mental representation of a text. According to Linssen et al. (2014), on a neurological level, the encoding of information in long-term memory, which is crucial for the formation of a mental representation of a text, is slowed down as a consequence of administering levodopa. However, although Linssen et al. (2014) found negative effects of administering levodopa on memory formation on a neurological level but not on a behavioural level, in the present study we found negative effects on memory formation (i.e., the mental representation of the text) on a behavioural level (i.e., performance on the reading comprehension outcome measures) and no effect on a neurological level. Additionally, although we found that increased levels of DA caused a speeding effect in slower readers, baseline reading speed was not related to reading comprehension, not as a main effect and not in interaction with condition. In contrast to Linssen et al.'s (2014) reasoning that increased DA might slowdown memory processes, the results of the present study do not suggest that readers suffered from a slowdown in memory processes as a consequence of increased levels of DA. A possible dopamine-related mechanism that could account for the negative effect of administering levodopa on reading comprehension is that participants in the present study experienced a flattened emotional responsiveness to information in the text during reading as a consequence of the pharmacological manipulation of DA levels in the brain. Pharmacological manipulation of DA levels using levodopa is aimed at increasing both tonic levels of DA, (i.e., sustained background levels), and phasic levels (i.e., short-term activations) of DA in the brain (Breitenstein et al., 2006a, b). However, Breitenstein et al. (2006a, b) argued, based on an experiment with healthy adults in which they pharmacologically manipulated only tonic levels of DA in the brain, that the dynamic combination of levels of phasic and tonic DA in the brain is a delicate balance (see also Linssen et al., 2014). Tonic increases in DA that are too large may lead to a reduction of phasic DA activity in healthy adults. As a consequence of pharmacologically increasing tonic DA, healthy adults in the experimental study of Breitenstein et al. (2006a, b) showed flattened emotional responsivity and impaired learning, which was, according to Breitenstein et al. (2006a, b) related to a decrease in phasic DA activity. If participants in the present study experienced a comparable flattened emotional responsiveness to information in the text during reading, this could have led to less task engagement during reading. In line with the engagement perspective of reading (see Klauda \& Guthrie, 2015), lowered engagement during reading could have led to a more superficial processing of the information in the text, resulting in a less coherent and complete mental representation of the text, hindering learning from text (van den Broek et al., 2005). Additionally, phasic DA appears to be particularly important for updating working memory knowledge (see Westbrook \& Braver, 2016), which is a crucial process for reading comprehension (Palladino et al., 2001). If an excessive increase in tonic DA leads to reduced phasic DA activity, readers could have experienced difficulties in updating working memory in the levodopa condition, and, as a consequence, they could have had difficulties updating the mental representation of the text.

An alternative explanation, in line with the results found by Hofmans et al. (2020) in their dopaminergic drug study on willingness to exert cognitive effort in a task, is also related to the engagement perspective of reading (Klauda \& Guthrie, 2015). Increased levels of DA may be related to reduced willingness to invest mental effort in a cognitive task (Westbrook et al., 2021), particularly for people with higher baseline DA levels. As we previously argued that in the present study students' levels of DA functioning seemed to be already located at or near the top of the inverted U-shape, one could argue that the female students in our sample would belong to a group with relatively high baseline levels of DA. If students were less willing to invest cognitive effort in the reading task as a consequence of administering levodopa, they were less engaged during reading which could have hindered a deep understanding of the text in this condition.

Another possible explanation for the negative effect of pharmacologically increasing DA on reading comprehension 
might be the difference in the reading task used in the present study compared to the word learning tasks used in previous research in which the effects of pharmacologically increasing DA on learning were tested (see Knecht et al., 2004; Breitenstein et al. 2006a, b; Linssen et al., 2014). In these studies, participants listened to single words being read to them. These tasks included much repetition, which could have caused boredom in participants, as was also argued by Knecht et al. (2004). In that case, pharmacologically increasing DA might have helped participants to perceive the task as more positive, or less boring, because increased DA helps participants to interpret neutral stimuli as more positive or salient (Tripp \& Wickens, 2008). In the case of reading comprehension, manipulating the experienced salience of information through pharmacologically increasing DA levels in the brain, which results in perceiving less salient information as salient and/or important, could have consequences for distinguishing main issues and side issues from the text. Participants' sensitivity to structural centrality of information in the text could have been hindered, which negatively influences reading comprehension (Kendeou et al., 2014).

\section{Limitations}

The present study provided new data on and insights into the consequences of DA signaling for attentional control and reading comprehension. However, some limitations of the study have to be taken into account when interpreting the results. The sample only included females. As a consequence, possible gender effects related to differences in DA levels in the brain between males and females, have not been taken into account. Additionally, the two subgroups included in our study were expected to differ in baseline levels of DA transmission in the brain. However, we did not have a direct measure of baseline levels of DA transmission and we, therefore, do not know whether students who were carrier of the DRD4-7R allele indeed had lower baseline levels of DA transmission compared to students who did not carry the DRD4-7R allele. Another possibility is that within group variability was greater than between group variability in baseline levels of DA.

In the present study we used one reading task in each condition using two comparable texts from the same book to minimize confounding from differences in writing style or difficulty level of the text. We cannot rule out that results would have been different when using another story or another type of text. Finally, and surprisingly, hardly any relations were found between the attentional control measures and the reading comprehension measures. Whereas most of the reading comprehension measures on text-level and those on word-level were mutually correlated, this was not the case for the attentional control measures. As a consequence, the results for attentional control and relations between drug effects on attentional control and reading comprehension have to be interpreted with some caution and future research is needed to gain insight into the attentional processes and possibly related processes that are related to DA signaling and reading comprehension.

\section{Suggestions for future research}

To further disentangle the dopamine-related mechanisms that might explain the effects of increased DA on attentional control and reading comprehension, future research should investigate the effects of increased DA on other cognitive processes that are related to attentional control and memory formation, such as working memory and goal-directed behaviour, that closely overlap with the neural correlates of attention (see e.g., Wass et al., 2012) and also rely on dopaminergic systems (see e.g., Cools \& D'Esposito, 2011). Additionally, motivational processes, such as the willingness to invest cognitive effort in a task have been showed to be related to fluctuations in DA levels in the brain (Westbrook et al., 2021). A complementary approach in which these cognitive and motivational processes are measured in both the levodopa and the placebo condition could provide further insight into the mechanisms underlying attentional control and reading comprehension. Additionally, the combination of physiological and behavioural measures could help to gain insight into both neurobiological and behavioural effects of DA functioning. In the present study, the outcomes on both physiological and self-report measures of attentional control during reading point in the same direction, i.e., neither a positive nor a negative effect of increased DA on attentional control. One exception to this was found for slower readers, who showed less fluctuations in attentional control as measured by the $S D$ in frontal TBR during reading after administering levodopa, but no difference in the self-report of attentional control was found between the placebo and levodopa condition for this group. In previous studies, effects of increased levels of DA on physiological measures and behavioural measures of cognitive processing also varied (e.g., ERP latencies vs. learning accuracy and learning speed, see Linssen et al., 2014). Finally, the effects of the number of levodopa dosages should be investigated on both a psychophysiological and behavioural level, because the effects of pharmacologically increasing DA differs across time spans of the experimental learning tasks used in previous studies and the present one. In the study of Linssen et al. (2014), only a negative psychophysiological effect of administering levodopa was found, but no behavioural effects. In the studies that used a similar daily dose, but a longer five-day word-learning intervention (Breitenstein et al., 2006a, b; Knecht et al., 2004), positive effects were found on a behavioural level. 


\section{Conclusions}

In conclusion, the results of the present study, which is to the best of our knowledge the first one testing the effects of pharmacologically increasing DA on reading comprehension including participants who might be expected to differ in DA uptake in the brain as a consequence of their genotype, showed that increased levels of DA did not influence attentional control during reading as measured by the average frontal TBR during reading and a retrospective self-report, but showed reduced fluctuations in attentional control in slow readers, as measured by $S D$ in frontal TBR. Additionally, increased levels of DA negatively influenced reading comprehension in healthy female university students. In other words, although the ability to attentively read and understand longer stretches of texts is crucial for success in academic, professional and personal life, pharmacologically optimizing reading comprehension and attentional control, is a complex issue that requires a more thorough understanding of the neurobiological processes and mechanisms underlying these complex skills. Because of diverging findings in the present study and previous studies regarding the effects of pharmacologically increasing DA on both a neurobiological and behavioural levels of cognitive processes and the difference in duration and complexity of learning tasks, more research and replication studies are needed to further unravel the dopamine-related mechanisms that could explain these effects.

Supplementary Information The online version contains supplementary material available at https://doi.org/10.1007/s12144-021-02363-6.

Funding The authors did not receive support from any organization for the submitted work.

Data availability The datasets generated and/or analysed during the current study are available from the corresponding author on reasonable request.

Code availability Not applicable.

\section{Declarations}

Conflicts of interest The authors have no conflicts of interest to declare that are relevant to the content of this article.

Ethics approval Before starting the research, its design and methodology were approved by the Education and Child Studies ethics committee of Leiden University (project ID: ECPW-2014/077) and the medical ethics committee of the Leiden University Medical Centre (project ID: NL49379.058.14). The procedures used in this study adhere to the tenets of the Declaration of Helsinki.

Clinical Trial Registration This study was registered with EudraCT European Clinical Trials Database (Identifier: 2014-001352-36).
Consent to participate Informed consent was obtained from all individual participants included in the study.

Consent for publication Participants signed informed consent regarding publishing their data.

Open Access This article is licensed under a Creative Commons Attribution 4.0 International License, which permits use, sharing, adaptation, distribution and reproduction in any medium or format, as long as you give appropriate credit to the original author(s) and the source, provide a link to the Creative Commons licence, and indicate if changes were made. The images or other third party material in this article are included in the article's Creative Commons licence, unless indicated otherwise in a credit line to the material. If material is not included in the article's Creative Commons licence and your intended use is not permitted by statutory regulation or exceeds the permitted use, you will need to obtain permission directly from the copyright holder. To view a copy of this licence, visit http://creativecommons.org/licenses/by/4.0/.

\section{References}

Ariza, M., Garolera, M., Jurado, M. A., Garcia-Garcia, I., Hernan, I., Sanchez-Garre, C., Vernet-Vernet, M., Sender-Palacios, M. J., Marques-Itturia, I., Pueyo, R., Segura, B., \& Narberhaus, A. (2012). Dopamine genes (DRD2/ANKK1-TaqA1 and DRD4-7R) and executive function: Their interaction with obesity. PLOS ONE, 7(7), e41482. https://doi.org/10.1371/journal.pone.0041482

Arrington, C. N., Kulesz, P. A., Francis, D. J., Fletcher, J. M., \& Barnes, M. A. (2014). The contribution of attentional control and working memory to reading comprehension and decoding. Scientific Studies of Reading, 18(5), 325-346. https://doi.org/10.1080/ 10888438.2014 .902461

Berke, J. D. (2018). What does dopamine mean? Nature Neuroscience, 21(6), 787-793. https://doi.org/10.1038/2Fs41593-018-0152-y

Bonvicini, C., Cortese, S., Maj, C., Baune, B. T., Faraone, S. V., \& Scassellati, C. (2020). DRD4 48 bp multiallelic variants as agepopulation-specific biomarkers in attention-deficit/hyperactivity disorder. Translational Psychiatry, 10(1), 1-19. https://doi.org/ 10.1038/s41398-020-0755-4

Bonvicini, C., Faraone, S. V., \& Scassellati, C. (2018). Common and specific genes and peripheral biomarkers in children and adults with attention-deficit/hyperactivity disorder. The World Journal of Biological Psychiatry, 19(2), 80-100. https://doi.org/10.1080/ 15622975.2017.1282175

Boulougouris, V., \& Tsaltas, E. (2008). Serotonergic and dopaminergic modulation of attentional processes. Progress in Brain Research, 172, 517-542. https://doi.org/10.1016/S0079-6123(08)00925-4

Breitenstein, C., Flöel, A., Korsukewitz, C., Wailke, S., Bushuven, S., \& Knecht, S. (2006a). A shift of paradigm: From noradrenergic to dopaminergic modulation of learning? Journal of the Neurological Sciences, 248(1-2), 42-47. https://doi.org/10.1016/j.jns. 2006.05.012

Breitenstein, C., Korsukewitz, C., Flöel, A., Kretzschmar, T., Diederich, K., \& Knecht, S. (2006b). Tonic dopaminergic stimulation impairs associative learning in healthy subjects. Neuropsychopharmacology, 31(11), 2552-2564. https://doi.org/10.1038/sj.npp. 1301167

Burgess, A. (2012). A Clockwork Orange (H. Damsma \& N. Miedema, Trans.). Athenaeum-Polak \& Van Gennep. (Original work published 1962).

Chang, F. M., Kidd, J. R., Livak, K. J., Pakstis, A. J., \& Kidd, K. K. (1996). The world-wide distribution of allele frequencies at the 
human dopamine D4 receptor locus. Human Genetics, 98(1), 91-101. https://doi.org/10.1007/s004390050166

Chiesa, A., Calati, R., \& Serretti, A. (2011). Does mindfulness training improve cognitive abilities? A systematic review of neuropsychological findings. Clinical Psychology Review, 31(3), 449-464. https://doi.org/10.1016/j.cpr.2010.11.003

Cohen, J. (1992). A power primer. Psychological Bulletin, 112(1), 155-159. https://doi.org/10.1037/0033-2909.112.1.155

Conners, F. A. (2009). Attentional control and the simple view of reading. Reading and Writing, 22(5), 591-613. https://doi.org/ 10.1007/s11145-008-9126-x

Cools, R., \& D'Esposito, M. (2011). Inverted-U-shaped dopamine actions on human working memory and cognitive control. Biological Psychiatry, 69(12), 113-125. https://doi.org/10.1016/j. biopsych.2011.03.028

Cools, R., \& Robbins, T. W. (2004). Chemistry of the adaptive mind. Philosophical Transactions of the Royal Society of London. Series A: Mathematical, Physical and Engineering Sciences, 362(1825), 2871-2888. https://doi.org/10.1098/rsta.2004.1468

Diamond, A., Briand, L., Fossella, J., \& Gehlbach, L. (2004). Genetic and neurochemical modulation of prefrontal cognitive functions in children. American Journal of Psychiatry, 161(1), 125-132. https://doi.org/10.1176/appi.ajp.161.1.125

Gough, P. B., \& Tunmer, W. E. (1986). Decoding, reading, and reading disability. Remedial and Special Education, 7(1), 6-10. https://doi.org/10.1177/2F074193258600700104

Gratton, G., Coles, M. G. H., \& Donchin, E. (1983). A new method for off-line removal of ocular artifact. Electroencephalography and Clinical Neurophysiology, 55(4), 468-484. https://doi.org/ 10.1016/0013-4694(83)90135-9

Green, C. S., \& Bavelier, D. (2012). Learning, attentional control, and action video games. Current Biology, 22(6), R197-R206. https://doi.org/10.1016/j.cub.2012.02.012

Hofmans, L., Papadopetraki, D., Van den Bosch, R., Määttä, J. I., Froböse, M., Zandbelt, B. B., Wesbrook, A., Verkes, R.-J., \& Cools, R. (2020). Methylphenidate boosts choices of mental labor over leisure depending on striatal dopamine synthesis capacity. Neuropsychopharmacology, 45, 2170-2179. https:// doi.org/10.1038/s41386-020-00834

Jokinen, P., Karrasch, M., Brück, A., Johansson, J., Bergman, J., \& Rinne, J. O. (2013). Cognitive slowing in Parkinson's disease is related to frontostriatal dopaminergic dysfunction. Journal of the Neurological Sciences, 329(1-2), 23-28. https://doi.org/ 10.1016/j.jns.2013.03.006

Kähkönen, S., Ahveninen, J., Pekkonen, E., Kaakkola, S., Huttunen, J., Ilmoniemi, R. J., \& Jääskeläinen, I. P. (2002). Dopamine modulates involuntary attention shifting and reorienting: An electromagnetic study. Clinical Neurophysiology, 113(12), 1894-1902. https://doi.org/10.1016/S1388-2457(02)00305-X

Karbach, J., \& Verhaeghen, P. (2014). Making working memory work: A meta-analysis of executive-control and working memory training in older adults. Psychological Science, 25(11), 2027-2037. https://doi.org/10.1177/0956797614548725

Kendeou, P., Van Den Broek, P., Helder, A., \& Karlsson, J. (2014). A cognitive view of reading comprehension: Implications for reading difficulties. Learning Disabilities Research \& Practice, 29(1), 10-16. https://doi.org/10.1111/ldrp.12025

Kjaer, T. W., Bertelsen, C., Piccini, P., Brooks, D., Alving, J., \& Lou, H. C. (2002). Increased dopamine tone during meditation-induced change of consciousness. Cognitive Brain Research, 13(2), 255259. https://doi.org/10.1016/S0926-6410(01)00106-9

Klauda, S. L., \& Guthrie, J. T. (2015). Comparing relations of motivation, engagement, and achievement among struggling and advanced adolescent readers. Reading and Writing, 28(2), 239269. https://doi.org/10.1007/s11145-014-9523-2
Knecht, S., Breitenstein, C., Bushuven, S., Wailke, S., Kamping, S., Flöel, A., Zwitserlood, P., \& Ringelstein, E. B. (2004). Levodopa: Faster and better word learning in normal humans. Annals of Neurology, 56(1), 20-26. https://doi.org/10.1002/ana.20125

Ko, J. H., Ptito, A., Monchi, O., Cho, S. S., Van Eimeren, T., Pellecchia, G., Ballanger, B., Rusjan, P., Houle, S., \& Strafella, A. P. (2009). Increased dopamine release in the right anterior cingulate cortex during the performance of a sorting task: a [11C] FLB 457 PET study. Neuroimage, 46(2), 516-521. https://doi.org/10.1016/ 2Fj.neuroimage.2009.02.031

Krimsky, M., Forster, D. E., Llabre, M. M., \& Jha, A. P. (2017). The influence of time on task on mind wandering and visual working memory. Cognition, 169, 84-90. https://doi.org/10.1016/j.cogni tion.2017.08.006

Linssen, A. M. W., Sambeth, A., Vuurman, E. F. P. M., \& Riedel, W. J. (2014). Cognitive effects of methylphenidate and levodopa in healthy volunteers. European Neuropsychopharmacology, 24(2), 200-206. https://doi.org/10.1016/j.euroneuro.2013.09.009

McGuigan, S., Zhou, S. H., Brosnan, M. B., Thyagarajan, D., Bellgrove, M. A., \& Chong, T. T. (2019). Dopamine restores cognitive motivation in Parkinson's disease. Brain, 142(3), 719-732. https:// doi.org/10.1093/brain/awy341

Moustafa, A. A., Herzallah, M. M., \& Gluck, M. A. (2013). Dissociating the cognitive effects of levodopa versus dopamine agonists in a neurocomputational model of learning in Parkinson's disease. Neurodegenerative Diseases, 11(2), 102-111. https://doi.org/10. $1159 / 000341999$

Mrazek, M. D., Franklin, M. S., Phillips, D. T., Baird, B., \& Schooler, J. W. (2013). Mindfulness training improves working memory capacity and GRE performance while reducing mind wandering. Psychological Science, 24(5), 776-781. https://doi.org/10.1177/ 2F0956797612459659

Munro, C. A., McCaul, M. E., Wong, D. F., Oswald, L. M., Zhou, Y., Brasic, J., Kuwabara, H., Kumar, A., Alexander, M., Ye, W., \& Wand, G. S. (2006). Sex differences in striatal dopamine release in healthy adults. Biological Psychiatry, 59(10), 966-974. https:// doi.org/10.1016/j.biopsych.2006.01.008

Nation, P. (2020). The different aspects of vocabulary knowledge. In S. Webb (Ed.), The Routledge handbook of vocabulary studies (pp. 15-29). Routledge.

Nieoullon, A. (2002). Dopamine and the regulation of cognition and attention. Progress in Neurobiology, 67(1), 53-83. https://doi.org/ 10.1016/S0301-0082(02)00011-4

Owen, A., Hampshire, A., Grahn, J. A., Stenton, R., Dajani, S., Burns, A. S., Howard, R. J., \& Ballard, C. G. (2010). Putting brain training to the test. Nature, 465, 775-778. https://doi.org/10.1038/natur e09042

Palladino, P., Cornoldi, C., De Beni, R., \& Pazzaglia, F. (2001). Working memory and updating processes in reading comprehension. Memory \& Cognition, 29(2), 344-354. https://doi.org/10.3758/ BF03194929

Putman, P., Verkuil, B., Arias-Garcia, E., Pantazi, I., \& van Schie, C. (2014). EEG $\theta / \beta$-ratio as a potential biomarker for attentional control and resilience against deleterious effects of stress on attention. Cognitive, Affective, \& Behavioral Neuroscience, 14(2), 782-791. https://doi.org/10.3758/s13415-013-0238-7

Sanders, J. G., Wang, H.-T., Schooler, J. W., \& Smallwood, J. (2017). Can I get me out of my head? Exploring strategies for controlling the self-referential aspects of the mind-wandering state during reading. The Quarterly Journal of Experimental Psychology, 70(6), 1053-1062. https://doi.org/10.1080/17470218.2016.12165 73

Schoots, O., \& Van Tol, H. H. M. (2003). The human dopamine D4 receptor repeat sequences modulate expression. The Pharmacogenomics Journal, 3(6), 343-348. https://doi.org/10.1038/sj.tpj. 6500208 
Shaywitz, S. E., \& Shaywitz, B. A. (2008). Paying attention to reading: The neurobiology of reading and dyslexia. Development and Psychopathology, 20(4), 1329-1349. https://doi.org/10.1017/S0954 579408000631

Smallwood, J., \& Schooler, J. W. (2015). The science of mind wandering: Empirically navigating the stream of consciousness. Annual Review of Psychology, 66, 487-518. https://doi.org/10.1146/annur ev-psych-010814-015331

Swart, E. K., Nielen, T. M. J., Shaul, S., \& Sikkema-de Jong, T. M. (2020). Frontal theta/beta-ratio (TBR) as potential biomarker for attentional control during reading in healthy females. Cognition, Brain, Behavior: An Interdisciplinary Journal, 24(3), 187-211. https://doi.org/10.24193/cbb.2020.24.11

Tabachnick, B. G., \& Fidell, A. S. (2007). Using multivariate statistics. Pearson Education.

Tripp, G., \& Wickens, J. R. (2008). Research Review: Dopamine transfer deficit: A neurobiological theory of altered reinforcement mechanisms in ADHD. Journal of Child Psychology \& Psychiatry, 49(7), 691-704. https://doi.org/10.1111/j.1469-7610.2007. 01851.x

Van den Broek, P., Rapp, D. N., \& Kendeou, P. (2005). Integrating memory-based and constructionist processes in accounts of reading comprehension. Discourse Processes, 39, 299-316. https:// doi.org/10.1080/0163853X.2005.9651685

Van Son, D., De Blasio, F. M., Fogarty, J. S., Angelidis, A., Barry, R. J., \& Putman, P. (2019). Frontal EEG theta/beta ratio during mind wandering episodes. Biological Psychology, 140, 19-27. https:// doi.org/10.1016/j.biopsycho.2018.11.003

Vijayraghavan, S., Wang, M., Birnbaum, S. G., Williams, G. V., \& Arnsten, A. F. (2007). Inverted-U dopamine D1 receptor actions on prefrontal neurons engaged in working memory. Nature $\mathrm{Neu}$ roscience, 10(3), 376-384. https://doi.org/10.1038/nn1846
Wass, S. V., Scerif, G., \& Johnson, M. H. (2012). Training attentional control and working memory: Is younger, better? Developmental Review, 32(4), 360-387. https://doi.org/10.1016/j.dr.2012.07.001

Westbrook, A., \& Braver, T. S. (2016). Dopamine does double duty in motivating cognitive effort. Neuron, $89,695-710$. https://doi.org/ 10.1016/j.neuron.2015.12.029

Westbrook, A., Frank, M. J., \& Cools, R. (2021). A mosaic of costbenefit control over cortico-striatal circuitry. Trends in Cognitive Sciences, 25(4), 710-721. https://doi.org/10.1016/j.tics.2021.04. 007

Zanesco, A. P., King, B. G., MacLean, K. A., Jacobs, T. L., Aichele, S. R., Wallace, B. A., Smallwood, J., Schooler, J. W., \& Saron, C. D. (2016). Meditation training influences mind wandering and mindless reading. Psychology of Consciousness: Theory, Research, and Practice, 3(1), 12-32. https://doi.org/10.1037/cns0000082

Zhou, P., Prat, C., Yamasaki, B. L., \& Stocco, A. (2020). Monitoring of attentional oscillations through Spectral Similarity Analysis predicts reading comprehension. Brain and Language, 200, 104709. https://doi.org/10.1016/j.bandl.2019.104709

Zwaan, R. A., Langston, M. C., \& Graesser, A. C. (1995). The construction of situation models in narrative comprehension: An event-indexing model. Psychological Science, 6(5), 292-297. https://doi.org/10.1111/2Fj.1467-9280.1995.tb00513.x

Publisher's note Springer Nature remains neutral with regard to jurisdictional claims in published maps and institutional affiliations. 